\title{
The Effect of Brucellosis on Women's Health and Reproduction
}

\author{
Mertihan Kurdoglu ${ }^{1^{*}}$, Orkun Cetin ${ }^{2}$, Zehra Kurdoglu ${ }^{3}$, Hayrettin Akdeniz ${ }^{4}$
}

\begin{abstract}
Due to its potential harmful effects on the general health and reproductive life of the women, in the light of available literature, it was aimed to review the effect of human brucellosis on women's health and reproduction. Data from 75 reports belonging to the years 1917 through 2015, obtained via a search on various internet sources by the words "Brucella", "brucellosis," "women's health," "human pregnancy," "human reproduction," "abortion," "preterm birth," "intrauterine fetal demise," and "intrauterine fetal death" were used to characterize basic microbiological features together with the risk factors, clinical presentations and complications of the human brucellosis related to various aspects of reproductive well-being. A high rate of spontaneous abortion was a more consistent finding rather than high rates of preterm delivery and intrauterine fetal death in pregnant women with brucellosis. The occurrence of abortion was not associated with the magnitude of serum agglutination titre or the clinical type of disease. The novel replication profiles of Brucella in human trophoblasts give insights into the pathogenesis of infectious abortion. Brucellosis is a risk factor for women's general health and reproduction as well as for many obstetric complications during pregnancy, of which spontaneous abortion is the mostly known. In order to prevent the disease and these complications, education of the women, especially the poor ones of childbearing age with low educational level is strongly advised. When the infected women present for medical care, an appropriate antimicrobial therapy should be started promptly.

Keywords: Brucellosis, Health, Pregnancy, Reproduction, Women
\end{abstract}

\section{Introduction}

Brucellosis is a zoonotic disease of worldwide distribution which still remains endemic in some developing countries, causing devastating economic losses. Since it is transmissible to humans through direct contact with infected animals, consumption of their milk and dairy products, or inhalation of contaminated aerosols, it is considered a big threat for public health. At this point, the effect of Brucella infection on women's health and reproduction gains an extraordinary importance due to its potential harmful effects on female reproductive system and pregnancy. Therefore, in this report we aimed to review the available literature related to human brucellosis in order to characterize the basic microbiological features as well as the risk factors and clinical presentations of the disease and its complications related to various aspects of reproductive health.

\section{Materials and Methods}

In order to look for original articles, review articles, case series, case reports and editorials related to the effects of brucellosis on women's health and reproduction, various internet engines including PubMed, Up To Date, Google, Google Scholar and Cochrane Library were searched between February 2015 and June 2015. Directly or indirectly related information from 75 reports, the earliest reported in 1917 and the latest in 2015 were identified. The words used during the search process were "Brucella," "brucellosis," "women's health," "human pregnancy," "human reproduction," "abortion," "preterm birth," "intrauterine fetal demise," and "intrauterine fetal death".

\section{Results}

General Features of Brucella Species and Infection The main pathogenic species worldwide are Brucella abortus (B. abortus), responsible for bovine brucellosis, Brucella melitensis (B. melitensis), the main etiologic agent of ovine and caprine brucellosis, and Brucella suis (B. suis), which has a wide host range, not being confined to swine (1). B. melitensis is responsible for the majority of human infections and is primarily food-borne. B. abortus and $B$. suis infections are generally sporadic and Brucella canis infections are the least common in humans and are generally laboratory-acquired $(2,3)$. 
In their natural hosts, Brucella spp. tend to cause chronic infections that are mild or asymptomatic. In most animals (e.g., B. abortus infection in cattle), organisms proliferate in the uterus and in the mammary glands. The bacteria localize in the reproductive tissues of ruminants, which are rich in mesoerythritol. Erythritol stimulates the multiplication of Brucella spp. This accounts for the main symptoms of brucellosis in animals -sterility or abortion. Erythritol is not present in human tissue. Many animals recover from the infection spontaneously, but continue to shed the bacteria in large numbers for varying times in the products of conception, in urine, vaginal secretions, and milk. Brucella spp. are also shed outside when the animals are slaughtered $(2,3)$.

The survival of Brucella outside the animal organism is variable. The duration of survival of Brucella in moist soil, in dung spread on the ground, has been reported to be 70-80 days, in dust varying from 15 to 40 days, depending on the ambient humidity (4). The organisms are capable of survival for 11 weeks in aborted fetuses; for 3-4 weeks in milk and ice cream; they can survive in fresh cheese for several months (5). Boiling and pasteurizing the milk kill the bacterium. Brucella also die when the milk goes sour or lactic acid fermentation occurs. The bacterium is also sensitive to heating, ionized radiation, and disinfectants (6). Humans are infected by various routes including ingestion of unpasteurized dairy products, direct contact with infected animals or their secretions through bruises and lacerations on the skin, inhalation of infected aerosols, or inoculation into the conjunctival sac of the eyes. Milk is the main food product serving as a vector for Brucella. Consumption of fresh, raw milk from animals is traditional, particularly in Saudi Arabia and other Arabic countries, which have a high incidence of brucellosis (7). Different kinds of fresh cheese are certainly the foodstuffs responsible for human brucellosis, especially goat and ewe cheeses. In developed countries, some human infections are associated with meat packing and dairy-related occupations (3).

Individuals considered at risk for contracting brucellosis include dairy farmers, livestock handlers, slaughterhouse employees, veterinarians, and laboratory personnel. Children may become infected in rural areas of developing countries if they live in close proximity with domestic animals. Although human-to-human transmission is quite rare, congenitally and sexually transmitted cases are reported as well. Self-inoculation with live Brucella vaccine is a recognized risk among veterinary surgeons. Laboratory workers are at risk of acquiring brucellosis through the inhalation of aerosols. This has occurred when handling as yet unidentified Gram-negative coccobacilli without adequate safety precautions (2).

The organism has a very low infectious dose (100 organisms or fewer). Mishandling and misidentification of the organism is often associated with laboratory transmission of the organism. Because infections related to blood transfusion and bone marrow transplantation are reported, questioning blood donors for symptoms of brucellosis and the use of diagnostic tests can be considered in endemic areas (6).

The true incidence of human brucellosis is unknown. According to the World Health Organization (WHO) report 500000 cases of brucellosis are reported each year from around the world. The reported incidence and prevalence of the disease vary widely from country to country. B. abortus is more prevalent in the United States and northern Europe, whereas B. melitensis is more common in Latin America countries, the Mediterranean basin (in particular Portugal, Spain, the South of France, Italy, Greece, and Turkey), Arab peninsula, and Indian subcontinent (2). Some areas, such as Peru, Kuwait, and Saudi Arabia, are hyper-endemic for Brucella infection. In Turkey, brucellosis is common especially in the Middle, East and Southeast Anatolian regions. The seropositivity rate was found to be $1.8 \%$ in the healthy population and $6 \%$ in high-risk occupational groups (veterinarians, workers in abattoirs, butchers, etc.) in a multicenter seroprevalence study in Turkey (8). In a seroprevalence study from Saudi Arabia, the seropositivity rate for brucellosis was reported to be $15 \%(9)$.

In the United States, as an example of a developed country, brucellosis is seen sporadically, and occurred in the Mexican border region at a rate eight times the national rate. There is also a resurgence of interest in brucellosis because of its potential as a bioweapon. This lies in the fact that transmission through a spray is possible as has been reported with human contamination during abortion of infected animals or bacterial spraying in laboratories (10). With increasing availability and popularity of international travel, many brucellosis cases diagnosed in US residents occur in people who have visited countries where the organism is endemic in ovine/bovine herds and unpasteurized dairy products. Infection partly reflects participation in aspects of a foreign culture that are so appealing to travellers (i.e., "living like the natives do") (3).

\section{Pathogenicity and Virulence}

Brucella spp. are facultative intracellular organisms, surviving and multiplying within cells of reticuloendothelial system (RES) and their disease spectrum is partially explained by the ability of the organism to evade host defense mechanisms by virtue of intracellular existence. Survival and multiplication of Brucella organisms in phagocytic cells are features essential to establishment, development, and chronicity of the disease (5).

Soon after entry into the body, the bacteria are ingested by polymorphonuclear and mononuclear phagocytes. After ingestion by phagocytes, the organisms proliferate in the local lymph nodes. The infection spreads hematogeneously to tissues rich in elements of RES, including the liver, bone marrow, lymph nodes and spleen. Organisms may also localize in other tissues, including joints, the central nervous system, the heart and the kidneys (2). Brucellae form granulomas made up of epitheloid cells, polymorphonuclear leukocytes, lymphocytes, and giant cells in tissues and organs. Granulomas are known to be more 
frequent in $B$. abortus infections. Although toxemia is commonly observed in B. melitensis, abscess formation in joints and spleen is more often related to B. suis (6).

Multiplication continues within macrophages and monocytes, and eventually the cells are killed, releasing the organisms. The "undulant" waxing-and-waning fever pattern seen in brucellosis is associated with the periodic release of bacteria and their components from phagocytic cells. Release of bacteria into the peripheral circulation results in hematogenous seeding of other organs and tissues, thereby leading to the protean clinical manifestations of human brucellosis. Relapses and recurrences of illness are kept in check to some degree by a balance between the virulence of the organism and the presence of an intact, functional cellular immune response. As with other intracellular pathogens, humoral antibodies are produced, but cellular immune defense mechanisms are required to kill the bacteria (3).

The clinical spectrum of brucellosis depends on many factors, including the immune status of the host, the presence of other underlying diseases or conditions, and the species of infecting organisms. The greater virulence of B. melitensis and $B$. suis has been supported by in vivo studies with experimentally infected animals and by in vitro work examining phagocytosis, intracellular survival, and lymphocyte responses to the different species. Disease caused by $B$. abortus and $B$. canis are insidious in their onset, but tend to cause milder constitutional symptoms and less severe complications (3).

Cellular immunity has a fundamental role in controlling the disease. Although the presence of specific antibodies is of utmost importance in diagnosis, they play a limited role in the immune response. The IgM antibodies increase in the first week and the IgG antibodies in the second. After 4 weeks of rising both Ig levels decrease rapidly through a successful treatment. Furthermore, IgG levels decrease faster than IgM levels with treatment. Even after eradication of active infection, IgM antibodies can remain positive in low titers for months or even years. A high level of IgG and IgA antibodies for longer than 6 months is a sign of chronic infection or relapse (6).

\section{Clinical Manifestations}

Brucellosis usually causes abortion and sterility in animals. It may also lead to a variety of clinical features, such as fever and septicemia, and even multiple organ involvement, in humans. As brucellosis is one of the great imitators in the world of infectious diseases, it can simulate various multisystem diseases, showing wide clinical polymorphism, which frequently leads to misdiagnosis and treatment delays, further increasing the complication rates. It may progress clinically as an acute, subacute, subclinical or chronic infection $(8,11,12)$. Since Brucella spp. are intracellular bacteria, relapse is often seen. The clinical manifestations of brucellosis vary greatly, ranging from asymptomatic infection to serious, debilitating disease. After an incubation period of 2 to 4 weeks, the onset of disease is commonly insidious (5).
Brucellosis can involve any organ or system in the body. The most frequent complaints are arthralgia, fever, and fatigue seen in up to $75 \%$ to $100 \%$ of the cases followed by sweating, malodorous perspiration, lack of appetite, myalgia, chills, depression, weight loss, headache, and back pain. The most common clinical findings are undulant fever and hepatomegaly in one third to one half of patients, followed by splenomegaly, peripheral arthritis, sacroiliitis, scrotal swelling, neck stiffness, and lymphadenopathy. Some patients present with focal or localized infections. Then, it may present with subtle manifestations which may be unrecognized for many years $(2,6,8)$.

Complications can occur, osteoarticular such as arthritis; spondylitis (13); central nervous system (14); urogenital (15); pulmonary (16); gastrointestinal (17) and renal complications (18); hematologic (19-21); cutaneous $(12,22)$, ocular (8) and cardiovascular, especially endocarditis (8). If we talk about our experience with brucellosis, we reported a 70-year-old female patient who was diagnosed with brucellosis and presented with mass formation resembling a tumor (22). The mass was protuberant, $10 \mathrm{~cm}$ from the skin surface with a diameter of $15 \mathrm{~cm}$, located at the inferior-lateral region of the left scapula. B. melitensis was yielded from culture of mass fluid. The patient responded to ceftriaxone, rifampin and doxycycline therapy and recovered without any sequela at the end of surgery and 3 months of medical treatment. In another paper (23), we presented a brucellosis lymphadenitis case in the right side of the neck in a 20 years old female patient, presenting with a mass formation in the soft tissue mimicking scrofuloderma, with dimensions of $10 \times 6 \times 4 \mathrm{~cm}$. After 6 months of brucellosis treatment, the mass markedly disappeared. For the first time in the literature, we reported the association of ascites, hearing loss and pancytopenia in brucellosis (17). A 25-year-old female patient was hospitalized with fever, hearing loss, ascites and pancytopenia. Cultures from bone marrow and ascites yielded growth of B. melitensis and Brucella standard tube agglutination was found to be positive at a titer of $1 / 1280$. The patient completely recovered by the sixth week following combined antibacterial treatment of ciprofloxacin, rifampin and doxycline. Relapse is considered an important feature of brucellosis; it is associated with delayed initiation of treatment, ineffective antibiotic therapy, and focal infections (5). Owing to its subtle nature, the disease is one of the leading cause of fever of unknown origin, especially in patients who have occupational exposure or have recently travelled in endemic areas and is one of the reasons for febrile neutropenia in endemic areas $(2,6)$.

\section{Approach to Clinical Diagnosis}

Diagnosis of brucellosis requires the assessment of medical history, clinical evaluation, and routine laboratory and radiologic tests combined with culture, serology, or polymerase chain reaction (PCR) assay. The routine laboratory tests are complete blood count (CBC), erythrocyte sedimentation rate (ESR), C-reactive protein, and liver function tests, although they are not specific for the di- 
agnosis, and wide patient variability is known to exist (6).

\section{Human Brucellosis During Pregnancy}

During the early years of clinical description of Malta fever, Eyre recognised the occurrence of active brucellosis during pregnancy for the first time in 1908, with a statement of "pregnancy frequently synchronizes with an attack of Malta fever and the course of pregnancy is unaffected, although lactation is frequently curtailed" (24). Although it could not be proven microbiologically, De Forest et al proposed a correlation between abortion and active brucellosis in humans firstly in 1917 (25).

Humans in different age groups can be infected by Brucella species and there are limited numbers of studies about seroprevalence of brucellosis during pregnancy. It varied between $1.8 \%$ and $45.7 \%$ in the literature (26-28). The study of Kurdoglu et al demonstrated that $6.14 \%$ of brucellosis cases occurred in pregnant women in an endemic region of eastern Turkey. The cumulative incidence of pregnant brucellosis cases per 1000 deliveries were found 2.64 over a 5 -year period in the same study (29). The study in another endemic part of the world, Saudi Arabia by Khan et al showed that out of 545 cases of brucellosis at the hospital from 1983 through 1995, 92 (17\%) occurred in pregnant women. In the same study, the cumulative incidence of brucellosis per 1000 delivered discharges was found to be 1.3 (7). The incidence of brucellosis was $12.2 \%$ among pregnant women included in the study of Elshamy and Ahmad (30). In consistent with this study, Sharif et al reported that out of 513 pregnant women who were tested routinely, 18 were found to have a positive titre (3.5\%) (31). However, the incidence of brucellosis among pregnant women is not known in many developing countries (32).

There is controversy about the relationship between brucellosis and the outcome of pregnancy in humans. There is some evidence that brucellosis causes a higher rate of complications such as abortion, preterm labour and intrauterine fetal demise (IUFD) more frequently than do other bacterial infections (11). In the study of Kurdoglu et al, all pregnant women with brucellosis $(n=33)$ had positive serum agglutination titers with ranges from $1 / 160$ to $1 / 2560$ and the geometric mean titer was $1 / 320$. Meanwhile, there was no correlation between pregnancy outcome and antibody titer $(P>.05)$ (29). Prior researches could not find any relationship between human brucellosis and congenital abnormalities $(30,32,33)$.

Below, the complications which are highly linked to human brucellosis are discussed in detail:

\section{Abortions}

The incidence of spontaneous abortion among brucellosis cases during pregnancy varied between $7 \%$ and $51 \%$ in various studies (7,28-30,34-41). The first large series about correlation between abortion and brucellosis was reported in 1954 by Criscuolo and di Carlo with a total abortion rate of $10 \%$ reported in 200 cases of B. melitensis infection in pregnant women (42). The incidence of spon- taneous abortion in Kurdoglu et al study was $24.14 \%$ in 29 pregnant women with brucellosis whose pregnancy outcomes are known within a retrospective cohort of 33 cases in eastern Turkey (29). The results of the above research is similar to that performed by Elshamy et al in Saudi Arabia reporting an incidence of $27.7 \%$ among 55 women pregnant in the first trimester with positive Brucella antibodies (30). In the endemic area of Isfahan, Sarram et al reported that out of 51 women studied with second-trimester abortion, 6 showed clinical and laboratory signs of brucellosis (11.6\%) (41). In consistent with these studies, high abortion rates were reported in the studies of Madkour et al and Khan et al (40\% among 30 pregnant women, and 43\% among 92 pregnant women with acute brucellosis, respectively) $(7,38)$.

There is much debate on Brucella antibody titer and spontaneous abortion. The results of the studies by Kurdoglu et al (29) and Elshamy et al (30) showed that there was a significant difference between the patients with a titer of more than $1 / 160$ and less than $1 / 160$ in terms of abortion rates. When Elshamy et al included pregnant women with antibody titers for Brucella both less than 1/160 and more than $1 / 160$, they found the abortion rate as $27.7 \%$. When they included only the group of patients with titers more than $1 / 160$, the abortion rate was found to be $44.11 \%$ (30). The abortion rate was reported as $24.14 \%$ when Kurdoglu et al included only the cases with titers equal or more than $1 / 160$ (29). Sharif et al also concluded that if the titer was higher than $1 / 160$, the incidence of abortion was $17.6 \%$ compared to $7.7 \%$ if the titer was less than $1 / 160$ (31).

The association between maternal bacteremic status and spontaneous abortion was also a point of interest. Some authors stated that the presence of Brucella bacteremia does not contribute to spontaneous abortion. These authors also proposed that vaginal bleeding at presentation causes spontaneous abortion, because of an endotoxin which has a promotility effect on uterine smooth muscle cells $(43,44)$ despite the absence of bacteremia, the absence of erythritol in the human placenta and fetus, and the absence of specific histological abnormalities in the placenta. In consistent with these studies, Khan et al did not find any association between maternal bacteremia and abortion (7).

Khan et al study showed a notable high incidence of first and second trimester spontaneous abortions in pregnancies with active brucellosis (7). Additionally, habitual abortion in chronic brucellosis is associated with an allergic mechanism. Recurrent bacteremia and antigen-antibody reaction stimulates desensitization which induces contraction of myometrial fibers with histamine discharge (45). In contrast, Kurdoglu et al found no correlation between clinical types of brucellosis and habitual abortion (29).

Since Brucella is a facultative and intracellular bacteria, it causes persistant infection by surviving in macrophages in spite of the immune response (46). In host cells, early endosomes, late endosomes, and lysosomes transiently interact with Brucella-containing vacuoles (BCV) $(47,48)$. 
In early stages, BCVs include lysosomal membrane-associated protein 1 (LAMP 1). By acidification of BCVs, the expression of genes encoding the virulence factors such as the VirB type IV secretion system (T4SS) is induced (49). Brucella manipulates fusion with endoplasmic reticulum (ER) membranes addicted with VirB T4SS (50,51). By this way, Brucella reproduces within ER-derived compartments in both phagocytes $(47,50,52)$, and in trophoblasts of infected animals (53-56).

A recent study showed that Brucella replicates in several human trophoblast subpopulations and can interfere with the invasive capacity of extravillous trophoblast-like cells (57). This novel replication profiles of Brucella in human trophoblasts give insights into the pathogenesis of infectious abortion (58). It has also been hypothesised that laminin receptor 1 (LR1) which acts as a cell-surface receptor of laminin (a family of well-described extracellular matrix glycoproteins having many effects on cell adhesion, differentiation, migration, signalling and invasion) may also have a role in diminished invasive capacity of extravillous trophoblast-like cells in both animal and human abortions related to Brucella infections $(59,60)$.

\section{Intrauterine Fetal Demise}

Intrauterine fetal demise (IUFD) is thought to be a complication of pregnancy associated with brucellosis. Makhseed et al found a $10 \%$ IUFD rate among pregnant women who had brucellosis infection (acute or chronic), and Elshamy et al detected this rate as $20.58 \%$ among pregnant women with a titer of brucellosis more than 1/160 $(30,39)$. This was much lower than the finding in the study of Khan et al since they observed a fetal death rate of $2 \%$ in second and third trimesters of gestation (7). In the study of Kurdoglu et al from Turkey, IUFD rate was found as $3.45 \%$ in a group of 29 pregnant women with brucellosis (29). Acute febrile reaction, maternal bacteremia and disseminated intravascular coagulation are thought to be the main factors of IUFD during pregnancy $(30,61)$.

\section{Preterm Delivery}

Preterm delivery is another complication occurring in pregnancies with brucellosis infection. Elshamy et al. found the preterm delivery rate as $20.5 \%$ among pregnant women complicated with brucellosis and having antibody titers more than 1/160 (30). Khan et al detected a much lower rate than the one found in the study of Elshamy, as $3.26 \%$ among pregnant women with acute brucellosis (7). In the study of Kurdoglu et al, they found this rate as $6.9 \%$, and the highest rate of preterm delivery was found in the study of Hackmon et al, as $28.5 \%$. $(29,36)$. As a result, the preterm delivery rate in pregnancies complicated with brucellosis varied between $3.26 \%$ and $28.5 \%$ in previous studies. Additionally, Gulsun et al. demonstrated that the risk of low birth weight (LBW) is remarkably higher in pregnant women infected by Brucella (35).

\section{Congenital Brucellosis}

The first case of congenital brucellosis was reported in
1988 (62). There is limited information about transplacental transmission of Brucella and there are few cases of congenital brucellosis in newborns according to the literature (63-65). Congenital brucellosis does not have any characteristic symptoms or findings. Further, blood cultures are frequently ineffective due to the slowly growing nature of Brucella and need for special $\mathrm{CO}_{2}$-enriched media (66). Serologic tests are also important methods for clinical diagnosis. However, a negative serologic test should never exclude the diagnosis of brucellosis in neonates (63). Therefore, the differential clinical diagnosis of congenital brucellosis is very crucial. The main findings in congenital brucellosis cases reported in the literature was respiratory distress syndrome associated with sepsis, preterm birth and meconium aspiration syndrome $(33,66-68)$.

Brucella species can be transmitted transplacentally during delivery and by breast feeding in postpartum period (69). In endemic regions, the mother and newborn should be examined cautiously and an efficient drug therapy should be planned by the clinician as soon as brucellosis is diagnosed.

\section{Treatment of Brucellosis During Pregnancy}

There is much debate in the literature on the treatment options for brucellosis during pregnancy. It is clear that brucellosis should be treated to prevent maternal and fetal complications during pregnancy $(36,70,71)$. However, there is lack of evidence about brucellosis treatment in pregnancy. In the previous studies, it was declared that antimicrobial treatment has a preventative impact on spontaneous abortion and also reduces transmission of Brucella to the fetus. Antimicrobial drugs used during pregnancy must be effective and must have lowest side effects to the fetus. Rifampicine and trimetoprim/sulfamethoxazole combination is the mostly preferred choice for brucellosis during pregnancy in the literature $(72,73)$.

Monotherapy was preferred as a treatment option in some studies due to the potential side effects of antimicrobial drugs on the fetus. Rifampicine and trimetoprim/sulfamethoxazole are the alternative monotherapy regimens for brucellosis during pregnancy. However, both of these regimens are associated with high relapse rates of Brucella infection (74). Combination therapy throughout 6 weeks is commonly recommended treatment option for brucellosis during pregnancy (75).

\section{Conclusion}

In the light of available literature, it can be concluded that brucellosis in pregnancy is a risk factor for spontaneous abortion. Also, a high rate of spontaneous abortion is a more consistent finding rather than high rates of preterm delivery and intrauterine fetal death in this group of patients. Neither the magnitude of serum agglutination titer nor the clinical type of brucellosis seems to be associated with the occurrence of abortion. The novel replication profiles of Brucella in human trophoblasts give insights into the pathogenesis of infectious abortion. In order to prevent the disease and its complications in pregnancy, 
education of the people and especially of poor women of childbearing age with low educational level is advised. Prompt antimicrobial therapy should be given to the infected women when they present for medical care.

\section{Ethical issues}

Not applicable.

\section{Conflict of interests}

The authors have no conflicts of interest to disclose.

\section{Financial support}

The authors did not have any financial support related to writing of this paper.

\section{Acknowledgments}

The authors have no acknowledgements to disclose.

\section{References}

1. Mehmet D, Bilgehan A. Human brucellosis: an overview. Int J Infect Dis. 2003;7:173-182.

2. Slack MP. Gram-negative coccobacilli. Brucella species. In: Cohen J, WG Powderly, SM Opal, eds. Infectious Diseases. 2nd ed. Edinburg: Mosby Elsevier; 2004:2245-8.

3. Winn W, Allen S, Janda W, Koneman Eea. Brucella species. Koneman's Color Atlas and Textbook of Diagnostic Microbiology. 6th ed. New York: Lippincott Williams and Wilkins; 2006:482-91.

4. Roux J. Public health importance of brucellosis. In: Tümbay E, S Hilmi, Ö Anğ, eds. Brucella and Brucellosis in Man and Animals. İzmir: Ege University Press; 1991:3-10.

5. Till PM. Brucella. Baily and Scott's Diagnostic Microbiology. 13th ed. Edinburg: Mosby Elsevier; 2014:431-35.

6. Gül HC, Erdem H. Brucellosis (Brucella species). Principles and Practice of Infectious Diseases. 8th ed. Toronto: Elsevier; 2015:2584-89.

7. Khan MY, Mah MW, Memish ZA. Brucellosis in pregnant women. Clin Infect Dis. 2001;32(8): 1172-7. doi: $10.1086 / 319758$.

8. Buzgan T, Karahocagil MK, Irmak H, et al. Clinical manifestations and complications in 1028 cases of brucellosis: a retrospective evaluation and review of the literature. Int J Infect Dis. 2010;14(6):e469-78. doi: 10.1016/j.ijid.2009.06.031.

9. Al-Sekait MA. Seroepidemiology survey of brucellosis antibodies in Saudi Arabia. Ann Saudi Med. 1999;19(3):219-22.

10. Guihot A, Bossi P, Bricaire F. [Bioterrorism with brucellosis]. Presse Med. 2004;33(2):119-22.

11. Akdeniz $\mathrm{H}$, Irmak $\mathrm{H}$, Demiröz AP. Evaluation of brucellosis cases in Van region of Eastern Anatolia: A-3 Year Experience. Nagoya Med J. 1998;42(2):10110 .

12. Metin A, Akdeniz H, Buzgan T, Delice I. Cutaneous findings encountered in brucellosis and review of the literature. Int J Dermatol. 2001;40(7):434-8.

13. Adak B, Tekeoglu I, Kutluhan A, Akdeniz H, Sakarya ME, Ugras S. Brucellar oligoarthritis involving the left temporomandibular, left sternoclavicular and left ankle joints. Clin Exp Rheumatol. 1997;15(1):122-3.

14. Akdeniz H, Irmak H, Anlar O, Demiroz AP. Central nervous system brucellosis: presentation, diagnosis and treatment. J Infect. 1998;36(3):297-301.

15. Celen MK, Ulug M, Ayaz C, Geyik MF, Hosoglu S. Brucellar epididymo-orchitis in southeastern part of Turkey: an 8 year experience. Braz J Infect Dis. 2010;14(1):109-15.

16. Karahocagil MK, Akdeniz H.Highly elevated adenosine deaminase level in brucellar pleural effusion. Turk J Med Sci. 2008;38(1):73-6.

17. Tuncer I, Akdeniz H, Uygan I, Turkdogan K, Cekici S, Durmus A. A brucellosis case with ascites, hearing loss and pancytopenia. Turk J Gastroenterol. 2002;13(3):168-71.

18. Ceylan K, Karahocagil MK, Soyoral Y, et al. Renal involvement in Brucella infection. Urology 2009;73:1179-83. doi: 10.1016/j.urology.2008.01.063.

19. Akdeniz H, Irmak H, Seckinli T, Buzgan T, Demiroz AP. Hematological manifestations in brucellosis cases in Turkey. Acta Med Okayama. 1998;52(1):63-5.

20. Demir C, Karahocagil MK, Esen R, Atmaca M, Gonullu H, Akdeniz H. Bone marrow biopsy findings in brucellosis patients with hematologic abnormalities. Chin Med J (Engl). 2012;125(11):1871-6.

21. Dilek İ, Durmuş A, Karahocagil MK, et al. Hematological Complications in 787 Cases of Acute Brucellosis in Eastern Turkey. Turk J Med Sci. 2008;38(5):421-4.

22. Karsen H, Akdeniz H, Irmak H, et al. A brucellosis case presenting with mass formation suggestive for tumor in soft tissue. South Med J. 2007;100(11):11379. doi: 10.1097/SMJ.0b013e318157f657.

23. Karsen H, Karahocagil MK, Akdeniz H, Sunnetcioglu M, Evirgen O. A case of brucellosis lymphadenitis mimicking scrofuloderma. Eur J Gen Med. 2007;4:209-12.

24. Eyre JW. Melitensis septicaemia. Lancet. 1908:174752.

25. De Forest HP. Infectious abortions of cattle as a complication of pregnancy for women. Am J Obstet. 1917;76:221-9.

26. Abo-Shehada MN, Abu-Halaweh M. Seroprevalence of Brucella species among women with miscarriage in Jordan. East Mediterr Health J. 2011;17(11):871-4.

27. Mohammad KI, El Ghazaly MM, Zaalouk TK, Morsy AT. Maternal brucellosis and human pregnancy. J Egypt Soc Parasitol. 2011;41(2):485-96.

28. Seoud M, Saade G, Awar G, Uwaydah M. Brucellosis in pregnancy. J Reprod Med. 1991;36(6):441-5.

29. Kurdoglu M, Adali E, Kurdoglu Z, et al. Brucellosis in pregnancy: a 6-year clinical analysis. Arch Gynecol Obstet. 2010;281(2):201-6. doi: 10.1007/s00404-0091106-0. 
30. Elshamy M, Ahmed AI. The effects of maternal brucellosis on pregnancy outcome. J Infect Dev Ctries. 2008;2(3):230-4.

31. Sharif A, Reyes Z, Thomassen P. Screening for brucellosis in pregnant women. J Trop Med Hyg. 1990;93(1):42-3.

32. Karcaaltincaba D, Sencan I, Kandemir O, GuvendagGuven ES, Yalvac S. Does brucellosis in human pregnancy increase abortion risk? Presentation of two cases and review of literature. J Obstet Gynaecol Res. 2010;36(2):418-23. doi: 10.1111/j.14470756.2009.01156.x.

33. Mesner O, Riesenberg K, Biliar N, et al. The many faces of human-to-human transmission of brucellosis: congenital infection and outbreak of nosocomial disease related to an unrecognized clinical case. Clin Infect Dis. 2007;45(12):e135-40. doi: 10.1086/523726.

34. Figueroa Damian R, Rojas Rodriguez L, Marcano Tochon ES. Brucellosis in pregnancy: course and perinatal results (in Spanish). Ginecol Obstet Mex. 1995;63:190-5.

35. Gulsun S, Aslan S, Satici O, Gul T. Brucellosis in pregnancy. Trop Doct. 2011;41(2):82-4. doi:10.1258/ td.2011.100386.

36. Hackmon R, Bar-David J, Bashiri A, Mazor M. Brucellosis in pregnancy (in Hebrew). Harefuah. 1998;135(1-2):3-7, 88.

37. Lulu AR, Araj GF, Khateeb MI, Mustafa MY, Yusuf AR, Fenech FF. Human brucellosis in Kuwait: a prospective study of 400 cases. Q J Med. 1988;66(249):39-54.

38. Madkour MM. Pregnancy and brucellosis. In: Madkour MM, editor. Brucellosis. London: Butterworth; 1989:197-204.

39. Makhseed M, Harouny A, Araj G, Moussa MA, Sharma P. Obstetric and gynecologic implication of brucellosis in Kuwait. J Perinatol. 1998;18(3):196-9.

40. Roushan MR, Baiani M, Asnafi N, Saedi F. Outcomes of 19 pregnant women with brucellosis in Babol, northern Iran. Trans R Soc Trop Med Hyg. 2011;105(9):540-2. doi: 10.1016/j.trstmh.2011.06.003.

41. Sarram M, Feiz J, Foruzandeh M, Gazanfarpour P. Intrauterine fetal infection with Brucella melitensis as a possible cause of second-trimester abortion. Am J Obstet Gynecol. 1974;119(5):657-60.

42. Criscuolo E, Di Carlo FC. Abortion and other gynecological and obstetrical disorders in brucellosis (in Spanish). Rev Fac Cienc Med Cordoba 1954;12(3):321-30.

43. Ganado W, Bannister W. Bacteraemia in human brucellosis. Br Med J. 1960;1(5173):601-3.

44. Urbaschek B. Motility-promoting effect of the Brucella abortus and Brucella melitensis endotoxin on the smooth uterine muscle. Nature. 1964;202:8834.

45. Fernihough TJ, Munoz WP, Mahadeyo I. The role of Brucella abortus in spontaneous abortion among the black population. S Afr Med J. 1985;68(6):379-80.

46. Memish Z, Mah MW, Al Mahmoud S, Al Shaalan
M, Khan MY. Brucella bacteraemia: clinical and laboratory observations in 160 patients. J Infect. 2000;40(1):59-63.

47. Pizarro-Cerda J, Meresse S, Parton RG, et al. Brucella abortus transits through the autophagic pathway and replicates in the endoplasmic reticulum of nonprofessional phagocytes. Infect Immun. 1998;66(12):5711-24.

48. Starr T, Ng TW, Wehrly TD, Knodler LA, Celli J. Brucella intracellular replication requires trafficking through the late endosomal/lysosomal compartment. Traffic. 2008;9(5):678-94. doi: 10.1111/j.16000854.2008.00718.x.

49. Porte F, Liautard JP, Kohler S. Early acidification of phagosomes containing Brucella suis is essential for intracellular survival in murine macrophages. Infect Immun. 1999;67(8):4041-7.

50. Celli J, de Chastellier C, Franchini DM, Pizarro-Cerda J, Moreno E, Gorvel JP. Brucella evades macrophage killing via VirB-dependent sustained interactions with the endoplasmic reticulum. J Exp Med. 2003;198(4):545-56. doi: 10.1084/jem.20030088.

51. Celli J, Salcedo SP, Gorvel JP. Brucella coopts the small GTPase Sar1 for intracellular replication. Proc Natl Acad Sci U S A. 2005;102(5):1673-8. doi: 10.1073/ pnas.0406873102.

52. Salcedo SP, Marchesini MI, Lelouard H, et al. Brucella control of dendritic cell maturation is dependent on the TIR-containing protein Btp1. PLoS Pathog. 2008;4(2):e21. doi: 10.1371/journal.ppat.0040021.

53. Anderson TD, Cheville NF. Ultrastructural morphometric analysis of Brucella abortus-infected trophoblasts in experimental placentitis. Bacterial replication occurs in rough endoplasmic reticulum. Am J Pathol. 1986;124(2):226-37.

54. Gorvel JP, Moreno E. Brucella intracellular life: from invasion to intracellular replication. Vet Microbiol. 2002;90(1-4):281-97.

55. Guzman-Verri C, Gonzalez-Barrientos R, HernandezMora G, et al. Brucella ceti and brucellosis in cetaceans. Front Cell Infect Microbiol. 2012;2: 3. doi: 10.3389/fcimb.2012.00003.

56. Meador VP, Deyoe BL. Intracellular localization of Brucella abortus in bovine placenta. Vet Pathol. 1989;26(6):513-5.

57. Salcedo SP, Chevrier N, Lacerda TL, et al. Pathogenic brucellae replicate in human trophoblasts. J Infect Dis 2013;207(7):1075-83. doi: 10.1093/infdis/jit007.

58. O'Callaghan D. Novel replication profiles of Brucella in human trophoblasts give insights into the pathogenesis of infectious abortion. J Infect Dis 2013;207(7):1034-6. doi: 10.1093/infdis/jit010.

59. Kurdoglu M, Kurdoglu Z. What is the role of laminin receptor 1 in human reproduction? International Journal of Women's Health and Reproduction Science. 2015;3(2):118-9. doi: 10.15296/ijwhr.2015.24.

60. Kurdoglu M, Sendag S, Kurdoglu Z. Is there a role of laminin receptor-1 in Brucella-related abortions? 
Reprod Domestic Animals. 2015;50:48. doi: 10.1111/ rda.12498.

61. Ketty S, Ebraheim N, Ismail N. Brucellosis in humans. Tehran, Iran: Research Centre on Brucellosis; 1997.

62. Lubani MM, Dudin KI, Sharda DC, et al. Neonatal brucellosis. Eur J Pediatr. 1988;147(5):520-2.

63. al-Eissa YA, al-Mofada SM. Congenital brucellosis. Pediatr Infect Dis J. 1992;11(8):667-71.

64. Giannacopoulos I, Eliopoulou MI, Ziambaras T, Papanastasiou DA. Transplacentally transmitted congenital brucellosis due to Brucella abortus. J Infect. 2002;45(3):209-10.

65. Singer R, Amitai Y, Geist M, et al. Neonatal brucellosis possibly transmitted during delivery. Lancet. 1991;338(8759):127-8.

66. Poulou A, Markou F, Xipolitos I, Skandalakis PN. A rare case of Brucella melitensis infection in an obstetrician during the delivery of a transplacentally infected infant. J Infect. 2006;53(1):e39-41. doi: 10.1016/j.jinf.2005.09.004

67. Dogan DG, Aslan M, Menekse E, Yakinci C. Congenital brucellosis: case report. Ann Trop Paediatr. 2010;30(3):229-31. doi: 10.1179/146532810 X12786388978724.

68. Mosayebi Z, Movahedian AH, Ghayomi A, Kazemi B.
Congenital brucellosis in a preterm neonate. Indian Pediatr. 2005;42(6):599-601.

69. Koklu E, Buyukkayhan D, Akcakus M, Kurtoglu S, Koklu S, Gunes T. Brucellosis with pulmonary involvement in a premature infant. Ann Trop Paediatr. 2006;26(4):367-70. doi: 10.1179/146532806X152917.

70. Kiki I, Gundogdu M, Albayrak B, Bilgic Y. Thrombotic thrombocytopenic purpura associated with Brucella infection. Am J Med Sci. 2008;335(3):230-2. doi: 10.1097/MAJ.0b013e3180d09f19.

71. Ozbay K, Inanmis RA. Successful treatment of brucellosis in a twin pregnancy. Clin Exp Obstet Gynecol. 2006;33:61-2.

72. Locksmith G, Duff P. Infection, antibiotics, and preterm delivery. Semin Perinatol. 2001;25(5):295309.

73. Porreco RP, Haverkamp AD. Brucellosis in pregnancy. Obstet Gynecol. 1974;44(4):597-602.

74. Solera J. Update on brucellosis: therapeutic challenges. Int J Antimicrob Agents. 2010;36(suppl 1):S18-20. doi: 10.1016/j.ijantimicag.2010.06.015.

75. Peker N, Turan V, Ergenoglu M, Yeniel O. Brucellosis in adolescent pregnancy--case report and review of literature. Ginekol Pol. 2011;82(3):226-9.

Copyright $\odot 2015$ The Author(s); This is an open-access article distributed under the terms of the Creative Commons Attribution License (http://creativecommons.org/licenses/by/4.0), which permits unrestricted use, distribution, and reproduction in any medium, provided the original work is properly cited. 